\section{Essential fatty acid treatment of rats with experimental diabetes: comment}

\section{Dear Sir,}

In rats with streptozotocin-induced neuropathy, essential fatty acid (EFA) treatment retained normal erythrocyte velocity in sciatic nerve blood vessels [1]. While this was explained in terms of vasodilator prostanoids, it is also possible that improved blood flow was the result of change in the erythrocytes [2]. Streptozotocin injected at diabetogenic concentrations into rats stimulated an echinocytosis (unpublished observation) and echinocytes have been shown to impair capillary blood flow and to have a reduced oxygen loading and release capacity. Streptozotocindiabetic rats had significantly less sciatic nerve blood flow and endoneurial oxygen tension than controls [3].

EFA supplementation with Efamol improved filtrability of cigarette smokers' blood [4] and enhanced the rate of healing of leg ulcers in elderly patients [5]. Those studies were based on reports showing that prostaglandin $\mathrm{E}_{1}\left(\mathrm{PGE}_{1}\right)$ increased the fluidity of the erythrocyte lipid bilayer [6] and improved filtrability of rat and human erythrocytes, while $\mathrm{PGE}_{2}$ had the opposite effect [7].

Willis [8] drew attention to the differing roles of dihomogammalinolenic acid (DHGLA) in man and rodents. He pointed out that DHGLA ". . is the biosynthetic precursor for prostaglandin $E_{1}$ " and although arachidonic acid may be formed from DHGLA by delta-5-desaturase, ". . this enzymatic step is largely lacking in man as compared with rats and mice." That opinion is compatible with the experimental results of Manku et al. [9].

While the findings reported by Professor Tomlinson's group [1] are in accord with the expected benefits of $P G E_{1}$ on capillary blood flow in rats with an echinocytosis, it must be emphasised that echinocytic changes are not common in the blood of humans with diabetes. Erythrocyte shape analysis of blood samples from 74 patients with insulin-dependent diabetes showed that only 10 of $74(13.5 \%)$ had more than the normal upper $95 \%$ confidence interval for echinocytes. In contrast, none of the blood samples from 78 patients with non-insulin-dependent diabetes showed such changes. Even allowing for the possibility that many factors relating to the patients' diabetes could influence their erythrocyte shape, it seems that the type of erythrocyte change observed in rats with streptozotocin-induced diabetes is unusual in human diabetes. This conclusion implies that although $13.5 \%$ of insulindependent diabetic patients may respond to evening primrose oil, the use of other haemorheologic agents needs to be investigated for their'effects on the retention of normal erythrocyte velocity in neural vessels of patients with diabetes. Although Ferrari et al. [10] have described the long-term (4 years) benefits of treatment of diabetic patients with the haemorheologic agent pentoxifylline, they did not investigate nerve blood flow.

Sincerely,

L. O. Simpson

\section{References}

1. Stevens EJ, Lockett MJ, Carrington AL, Tomlinson DR (1993) Essential fatty acid treatment prevents nerve ischaemia and associated conduction anomalies in rats with experimental diabetes mellitus. Diabetologia 36:397-401

2. Simpson LO (1988) Altered blood theology in the pathogenesis of diabetic and other neuropathies. Muscle Nerve 11: $725-744$

3. Tuck RR, Schmeltzer JD, Low PA (1984) Endoneurial blood flow and oxygen tension in the sciatic nerve of rats with experimental diabetic neuropathy. Brain 107: 935-950

4. Simpson LO, Olds RJ, Hunter JA (1984) Changes in the rheological properties of blood in cigarette smokers taking Efamol: a pilot study. Proc Univ Otago Med Sch 62: 122-123

5. Simpson LO, Shand BI, Olds RJ (1986) The effects of dietary supplementation with Efamol on the healing rate of intractable ulcers. NZ Fam Physician 13: 68-70

6. Kury PG, Ramwell PW, McConnell HM (1974) The effect of prostaglandin $E_{1}$ and $E_{2}$ on the human erythrocyte as monitored by spin labels. Biochim Biophys Res Commun 56: 478-483

7. Rasmussen H, Lake W, Allen JE (1975) The effect of catecholamines and prostaglandins upon human and rat erythrocytes. Biochim Biophys Acta 411: 63-73

8. Willis AL (1984) Dihomogammalinolenic acid as the endogenous protective agent for myocardial infarction. Lancet II: 697

9. Manku MS, Morse-Fisher N, Horrobin DF (1988) Changes in human plasma essential fatty acid levels as a result of administration of linoleic and gamma-linolenic acid. Eur J Clin Nutr 42: 55-60

10. Ferrari E, Fioravanti M, Patti AL, Viola C, Solerte SB (1987) Effects of long-term treatment (4 years) with pentoxifylline on haemorheological changes and vascular complications in diabetic patients. Pharmatherapeutica 5:26-39 